\title{
As circulações de ideias entre Alemanha e Brasil: clínica, laboratório e eugenia
}

\author{
The circulation of ideas between Germany and Brazil: \\ clinic, laboratory and eugenics
}

\author{
La circulación de ideas entre Alemania y Brasil: \\ clínica, laboratorio y eugenesia
}

\begin{abstract}
CLÍNICA, LABORATÓRIO E EUGENIA: UMA HISTÓRIA TRANSNACIONAL DAS RELAÇÕES BRASIL-ALEMANHA. Muñoz P. Rio de Janeiro: Editora Fiocruz/Editora PUC-Rio; 2018. 395 p. ISBN 978-85-7541-620-4 (Editora Fiocruz); ISBN 978-85-8006-260-1 (Editora PUC-Rio).
\end{abstract}

doi: 10.1590/0102-311X00142219

Em Clínica, Laboratório e Eugenia: Uma História Transnacional das Relações Brasil-Alemanha, Pedro Muñoz, historiador da Ciência e da Saúde, professor do Departamento de História da Pontifícia Universidade Católica do Rio de Janeiro, debate as relações entre a psiquiatria alemã e a brasileira, no começo do século XX, numa abordagem histórica que tem como foco as circulações de ideias sobre os discursos biológicos na época, tomando como base a medicina mental, num amplo debate sobre as biopolíticas eugênicas.

O livro é resultado de sua tese de doutorado, engrandecido por material colhido em fontes primárias (arquivos pessoais e diplomáticos) no Brasil e na Alemanha. Ao enfocar a circulação de ideias dos cientistas nacionais e internacionais sobre as biopolíticas eugênicas, o autor trabalha com a narrativa de uma história da psiquiatria, que ganhou maior densidade durante o crescimento do nazismo na Alemanha, com a hegemonia das teorias degeneracionistas, biodeterministas e racialistas e suas repercussões e impasses para a psiquiatria brasileira.
Observando a primeira metade do século XX, identificam-se temas de grandes controvérsias, especialmente na Alemanha, no tocante às relações entre política e ciência. As teorias eugenistas e raciais estavam presentes também nas discussões da medicina mental e instrumentalizavam os discursos na época sobre as causas da suposta degeneração da população. Na Alemanha, a psiquiatria alemã desempenhou papel fundamental, uma vez que, segundo Muñoz, "esteve no centro das ações de extermínio impetradas pelos nazistas” ( $\mathrm{p}$. 18). As ciências, inclusive a psiquiatria, buscaram instrumentalizar as políticas que "modernizariam ou regenerariam” as sociedades, tendo em vista as ameaças biológicas ao corpo social.

Pedro Muñoz destaca as relações científicas e os intercâmbios teuto-brasileiros, em especial, as relações bilaterais entre Alemanha e Brasil. Do lado brasileiro, o autor discorre, em especial, sobre o papel que o médico Juliano Moreira - diretor do Hospício Nacional de Alienados - desempenhou no fortalecimento das relações científicas e do discurso biológico no Brasil, sobretudo com o movimento da higiene mental e da eugenia no país. Segundo Muñoz, o intercâmbio teuto-brasileiro na medicina mental iniciou quando Juliano Moreira foi professor na Cadeira de moléstias nervosas e mentais na Faculdade de Medicina da Bahia. Seus trabalhos sobre dermatologia e sifilografia repercutiram positivamente no exterior. Moreira foi, segundo Muñoz, um grande divulgador da medicina alemã no Brasil e um dos responsáveis pelo fim da hegemonia da medicina francesa no país. 
Do lado alemão, Muñoz destaca o papel do psiquiatra Emil Kraepelin - conhecido como o pai da moderna psiquiatria e genética psiquiátrica -, suas teorias e práticas, que influenciaram profundamente Moreira e a psiquiatria brasileira. Analisa também a recepção e a difusão da psiquiatria genética de Ernst Rüdin no Brasil, seus estudos sobre hereditariedade das doenças neuropsiquiátricas e as mudanças na assistência aos psicopatas ao longo dos anos de 1930, para problematizar o projeto de fundação do Instituto de Psiquiatria da Universidade do Brasil e do Instituto Teuto-Brasileiro de Alta Cultura. Discute, ainda, a preocupação de Wilhelm Griesinger, quem inaugurou os estudos do tecido nervoso, da anatomia e da fisiologia cerebral, em integrar os hospitais às universidades e a clínica ao laboratório.

O livro é denso e exigiu de Muñoz um profundo conhecimento sobre vários aspectos relacionados ao papel da medicina mental, que segundo o autor, buscou interferir na organização das sociedades nesse período. Quais os motivos da aproximação das comunidades científicas em medicina mental no Brasil e na Alemanha? E, como foram acionados os discursos biológicos da clínica, do laboratório e da eugenia nos dois lados do Atlântico? Essas são as preocupações de Muñoz para entender a circulação de ideias e da ciência psiquiátrica alemã no Brasil, pelo grupo de médicos brasileiros influenciado pelas teorias de Kraepelin, Rüdin e Griesinger.

Pedro Muñoz salienta o esforço de Kraepelin na busca de uma forma de pensar o lugar da psiquiatria como ciência, em sua interface com a pesquisa científico-experimental. Kraepelin foi responsável por novas metodologias e técnicas de pesquisa experimental $1 \mathrm{e}$, influenciado pelos trabalhos de Wilhelm Griesinger - "personagem central na história da psiquiatria alemã” e que ficou famoso pelo seu tratado sobre patologia e terapêutica das doenças mentais, publicado em 18452 -, considerava que a psicologia deveria ser um conhecimento construído junto à experiência de cada paciente.

Cabe destacar que nesse período o Brasil cultivava laços com duas tradições europeias antagônicas: a escola francesa - com forte foco na clínica (modelo anatomoclínico), com formação especializada e profissionalizante, via escolas isoladas, e a escola alemã, marcada pela pesquisa laboratorial, considerada função primordial das universidades. O modelo alemão enfatizava a importância da pesquisa na universidade, e mais do que isto, a "indissociabilidade" entre ensino, pesquisa e formação 3,4 .

Griesinger propôs hospitais urbanos integrados à universidade - o hospital como sede da clínica universitária. Esse seria o local de internação dos pacientes, mas também o local de ensino e pesquisa. No início do século XX, tanto os médicos alemães quanto os brasileiros, após amplos debates entre a clínica e o laboratório, não acreditavam mais no modelo asilar de confinamento como forma de assistência aos pacientes com desordens mentais.

É importante salientar que, assim como na Alemanha, no Brasil o movimento eugenista cresceu junto ao movimento nacionalista e ganhou força nos meios acadêmicos, políticos intelectuais e literários. No período da Primeira Guerra Mundial, o Brasil assistiu à geração de um novo nacionalismo. Mas, enquanto na Europa se discutiam questões voltadas para a degeneração racial, aqui se defendia a necessidade de regeneração social, embora existissem também correntes de pensamento adeptas das teorias do branqueamento e arianização da população brasileira 5 .

A classe médica brasileira se inseria na discussão sobre a necessidade de sanear os sertões, como ideologia de construção nacional. Ao mesmo tempo, essa visão nacionalista e regenerativa permearia o início das discussões do movimento eugenista brasileiro, que se ligou aos movimentos nacionalista e sanitarista iniciados no começo do século XX no país 6. Para Juliano Moreira, assim como para a maior parte dos médicos sanitaristas brasileiros, a degeneração era resultante das condições sanitárias, sociais e econômicas do país. Moreira criticava o reducionismo do determinismo biológico, racial e climático.

A partir de 1914, aprofundou-se o distanciamento entre as discussões de cientistas alemães e brasileiros sobre o movimento eugenista, e tornou-se ainda mais evidente ao se considerar que a eugenia no Brasil, neste período, e também na Era Vargas, tinha características mais ligadas às medidas da eugenia positiva e preventiva do que às da eugenia negativa, como as ações que começaram a ser adotadas na Alemanha de esterilização, eutanásia e segregação, e que estavam 
associadas aos ideais e mitos do pangermanismo e do arianismo. A psiquiatria alemã aprofundou as pesquisas científicas sobre a herança biológica e a higiene racial. Essa "psiquiatria biológica e genética” encontraria eco nas discussões sobre a teoria da degeneração.

Finalmente, Muñoz mostra em seu belo livro que o projeto nazista ampliou recursos para as pesquisas científicas nas universidades, um verdadeiro "balcão de oportunidades" para jovens pesquisadores, como Rüdin, pois incentivou as discussões sobre o determinismo biológico e o racismo científico, e permitiu a transformação da higiene racial em políticas públicas. Essa associação entre higiene racial e o Terceiro Reich foi, segundo o autor, quase simbólica e representou o "fim de tradições universitárias" e da pesquisa científica interdisciplinar e horizontalizada, com a demissão em massa de catedráticos neuropatologistas e psiquiatras defensores de um biologicismo mais brando. Em outras palavras, os estudos de Griesinger, levados a fundo por Kraepelin, cederam espaço para as pesquisas intermediadas por Rüdin, que defendia medidas radicais para reduzir o número de doentes mentais e "anormais degenerados" na Alemanha.

Lina Faria 1

1 Universidade Federal do Sul da Bahia, Porto Seguro, Brasil. linafaria1964@gmail.com

\section{Informação adicional}

ORCID: Lina Faria (0000-0002-6439-0760).

1. Facchinetti C, Muñoz P. Emil Kraepelin na ciência psiquiátrica do Rio de Janeiro, 19031933. Hist Ciênc Saúde-Manguinhos 2013; 20:239-62.

2. Pereira MEC. Griesinger e as bases da "Primeira psiquiatria biológica”. Rev Latinoam Psicopatol Fundam 2007; 10:685-91.

3. Kemp A, Edler F. A reforma médica no Brasil e nos Estados Unidos: uma comparação entre duas retóricas. Hist Ciênc Saúde-Manguinhos 2004; 11:569-85.

4. Almeida Filho N. Reconhecer Flexner: inquérito sobre produção de mitos na educação médica no Brasil contemporâneo. Cad Saúde Pública 2010; 26:2234-49.

5. Castro Santos LA. O pensamento sanitarista na Primeira República: uma ideologia de construção da nacionalidade. Dados Rev Ciênc Sociais 1985 ; 28:193-210.

6. Kobayashi E, Faria L, Costa MC. Eugenia e Fundação Rockefeller no Brasil: a saúde como proposta de regeneração nacional. Sociologias 2009; 22:314-51.

Recebido em 28/Jul/2019

Aprovado em 05/Ago/2019 